\title{
Erratum to: Evaluation and calibration of Blaney-Criddle equation for estimating reference evapotranspiration in semiarid and arid regions
}

\author{
Mohammad Mehdi Heydari - Hamid Reza Fooladmand • Ali Tajamoli • \\ Seyyed Hojjat Ghoreishi - Masoud Khodabakhshi Darbe-Esfahani • \\ Hadi Gilasi
}

Published online: 8 January 2015

(c) Springer-Verlag Berlin Heidelberg 2015

\section{Erratum to: Environ Earth Sci \\ DOI 10.1007/s12665-014-3809-1}

The authors would like to correct errors in the original publication as detailed below.

The correct version of the author lists is given here:

Mohammad Mehdi Heydari · Hamid Reza Fooladmand . Ali Tajamoli · Seyyed Hojjat Ghoreishi · Masoud Khodabakhshi Darbe-Esfahani · Hadi Gilasi

The online version of the original article can be found under doi:10.1007/s12665-014-3809-1.

\section{M. Heydari ( $\square)$}

Department of Water Engineering, College of Engineering, Ahvaz Branch, Islamic Azad University, Ahvaz, Iran

e-mail: mehdiheydari2010@yahoo.com

H. R. Fooladmand

Department of Water Engineering, Marvdasht Branch, Islamic

Azad University, Marvdasht, Iran

A. Tajamoli $\cdot$ S. H. Ghoreishi

Department of Water Engineering, College of Civil, South Tehran Branch, Islamic Azad University, Tehran, Iran

M. K. Darbe-Esfahani

Department of Construction Management and Engineering, College of Civil, Isfahan (Khorasgan) Branch, Islamic Azad University, Isfahan, Iran

H. Gilasi

Department of Chemical Engineering, Faculty of Chemistry, Isfahan University of Technology, 84156-83111 Isfahan, Iran
Mohammad Mehdi Heydari $(\square)$

Department of Water Engineering, College of Engineering, Ahvaz Branch, Islamic Azad University, Ahvaz, Iran e-mail: mehdiheydari2010@yahoo.com

Hamid Reza Fooladmand

Department of Water Engineering, Marvdasht Branch, Islamic Azad University, Marvdasht, Iran

Ali Tajamoli, Seyyed Hojjat Ghoreishi

Department of Water Engineering, College of Civil, South Tehran Branch, Islamic Azad University, Tehran, Iran

Masoud Khodabakhshi Darbe-Esfahani

Department of Construction Management and Engineering, College of Civil, Isfahan (Khorasgan) Branch, Islamic Azad University, Isfahan, Iran

Hadi Gilasi

Department of Chemical Engineering, Faculty of Chemistry, Isfahan University of Technology, 84156-83111, Isfahan, Iran

The complete paragraph in the subheading "Local calibration" is replaced as follows:

Local calibration

In order to calibrate the original coefficients $\mathrm{BC}$ equation $(a, b)$ using monthly data, a linear regression procedure was adopted. Considering the linear regression between $\mathrm{ET}_{0}$ as the dependent variable obtained from the FAO-56 PM method as reference, $T_{\text {mean }}$ as the independent variable and obtaining the $P$ value from the appropriate table (James 1988), the slope and intercept of the regression line can be calculated for each region and each month of the year (Fooladmand and Ahmadi 2009). Using the local calibrated coefficients $\left(a_{\text {cal }}, b_{\text {cal }}\right)$ instead 
of the original coefficients, Eq. (2) can be rewritten (hereafter as $\mathrm{CBC}$ )

$\mathrm{ET}_{0}=a_{\text {cal }}+b_{\text {cal }}\left[P\left(0.46 T_{\text {mean }}+8.13\right)\right]$.

Using the geographical coordinates of the stations and considering the $a_{\text {cal }}$ and $b_{\text {cal }}$ values, the spatial and temporal distribution maps of these coefficients were drawn for each month of the year (Fooladmand and Ahmadi 2009). To obtain these maps, geographic information system (GIS)-assisted methods were used. Contour maps of coefficients $\left(a_{\text {cal }}, b_{\text {cal }}\right)$ were obtained by inverse distance weighting (IDW) with power of one used for interpolation (Kravchenko and Bullock 1999).

The below reference is included in the reference list:

\section{Reference}

Fooladmand HR, Ahmadi SH (2009) Monthly spatial calibration of Blaney-Criddle equation for calculating monthly ETo in south of Iran. Irrig Drain 58:234-245

Kravchenko A, Bullock DG (1999) A comparative study of mol. 88:1650-1657. Interpolation methods for mapping soil properties. Agron J 91:393-400 